\title{
Of mice and marbles: Novel perspectives on burying behavior as a screening test for psychiatric illness
}

\author{
De Wet Wolmarans ${ }^{1}$ • Dan J. Stein ${ }^{2}$ - Brian H. Harvey ${ }^{3}$
}

Published online: 26 February 2016

(C) Psychonomic Society, Inc. 2016

\begin{abstract}
Burying forms part of the normal behavioral routine of rodents, although its expression is species-specific. However, it has been suggested that aberrant burying behavior, of which marble-burying (MB) is an example, may represent neophobic and/or compulsive-like behavior. In the present investigation, we assessed MB in an established animal model of obsessive-compulsive disorder (OCD) - namely, spontaneous stereotypy in the deer mouse - to establish whether high $(\mathrm{H})$ stereotypy is associated with neophobia and/or another compulsive endophenotype, i.e. MB, as compared to nonstereotypical (N) controls. A three-trial, one-zone MB test was performed over three consecutive evenings both before and after chronic treatment with high-dose $(50 \mathrm{mg} / \mathrm{kg} /$ day) oral escitalopram. Neophobia was measured via the number of marbles buried during the first pre- and posttreatment MB trials, and compulsive-like behavior via the number of marbles buried over all pre- and posttreatment MB trials. The data from the present study support earlier findings that
\end{abstract}

Electronic supplementary material The online version of this article (doi:10.3758/s13415-016-0413-8) contains supplementary material, which is available to authorized users.

Brian H. Harvey

brian.harvey@nwu.ac.za

1 Division of Pharmacology, North-West University, Potchefstroom, South Africa

2 Department of Psychiatry and Mental Health, MRC Unit on Anxiety \& Stress Disorders, University of Cape Town, Cape Town, South Africa

3 Center of Excellence for Pharmaceutical Sciences, MRC Unit on Stress and Anxiety Disorders, North-West University (Potchefstroom Campus), Hoffman Street, Potchefstroom 2520, South Africa burying is a normal behavioral routine (inherent burying behavior, IBB) that is expressed by all deer mice, irrespective of stereotypical cohort, and is not associated with either neophobia or compulsiveness. Indeed, chronic escitalopram treatment, which is similarly effective in treating clinical anxiety and OCD, as well as in attenuating $\mathrm{H}$ behavior, failed to influence IBB. Although $11 \%$ of the animals presented with a unique burying endophenotype (high burying behavior), escitalopram also failed to attenuate said behavior, necessitating further investigation as to its relevance. In conclusion, $\mathrm{MB}$ cannot be regarded as a measure of anxiety-like or compulsive behavior in the deer mouse model of OCD.

Keywords Marble-burying - Obsessive-compulsive disorder · Neophobia · Deer mouse - Animal model · Escitalopram

Burying, burrowing, and digging form part of the normal behavioral repertoire of rodents, in both the wild and the laboratory (Deacon, 2006; Smithers, 1983). These strain-specific behaviors are mostly aimed at searching for food, burying both noxious and harmless objects, and building adequate nurseries capable of protecting individuals against predators and providing suitable environments to breed (Smithers, 1983). Evidently, burying and digging are expressed in relatively nonanxiogenic scenarios (e.g., nesting, hoarding, foraging), as well as under anxiogenic circumstances (e.g., burying of noxious objects, confronting predators).

Defensive burying (Pinel \& Treit, 1978) can be defined as the process of moving loose bedding material vertically upward and over potentially harmful stimuli or sources of aversive stimulation (e.g., a shock prod). Due to the stressprovoking nature of an electric shock, defensive burying has been used as a measure of avoidance-dependent anxiety in a 
number of previous investigations (for a review, see De Boer $\&$ Koolhaas, 2003). Another anxiety-related form of burying (or neophobic burying) relates to novelty-induced anxiety (Diamant, Croiset, De Zwart, \& De Wied, 1991; TorresLista, López-Pousa, \& Giménez-Llort, 2015) following exposure to novel, but nonreactive and harmless, objects. In theory, whereas animals demonstrate nonhabituation toward defensive burying, neophobic burying should attenuate over time following repeated exposure to the same stimuli (Londei, Valentini, \& Leone, 1998).

However, an abundance of literature (Egashira et al., 2008; Londei et al., 1998; Njung'e \& Handley, 1991; Thomas et al., 2009) has demonstrated that rodents often persist in burying harmless forms of stimuli in the absence of anxiety-which, for the purpose of this article, will be referred to as inherent burying, of which marble-burying (MB) is a typical example. As such, it has been hypothesized that this represents nonfunctional repetitive behavior analogous to the behavioral symptoms of obsessive-compulsive disorder (OCD; Thomas et al., 2009; Umathe, Manna, \& Jain, 2012). Although some studies have employed $\mathrm{MB}$ as a measure of avoidance-related anxiety (Nicolas, Kolb, \& Prinssen, 2006), findings relating to nonhabituation to marbles in the absence of anxiety (Thomas et al., 2009) are more compatible with inherent than with defensive or neophobic burying. Indeed, MB is a screening test for potential OCD treatments (Egashira et al., 2008; Gyertyan, 1995; Millan, Girardon, Mullot, Brocco, \& Dekeyne, 2002). However, the test lacks illness specificity and has been used to model treatment response in impulsivity (Schneider \& Popik, 2007), autism (Angoa-Pérez, Kane, Briggs, Francescutti, \& Kuhn, 2013), and dementia (TorresLista et al., 2015).

Defensive, neophobic, and inherent burying often respond to the same pharmacological agents (De Boer \& Koolhaas, 2003; Nicolas et al., 2006). All three forms of burying have shown sensitivity to traditional anxiolytics - namely benzodiazepines (Nicolas et al., 2006; Njung'e \& Handley, 1991) and to various classes of noradrenergic and serotonergic antidepressants - e.g., desipramine, imipramine, citalopram, paroxetine, and fluvoxamine (Abe, Nakai, Tabata, Saito, \& Egawa, 1998; Broekkamp, Rijk, Joly-Gelouin, \& Lloyd, 1986; Millan et al., 2001). Haloperidol (Nicolas et al., 2006) and chlorpromazine (Bruins Slot, Bardin, Auclair, Depoortere, \& Newman-Tancredi, 2008), which are traditional antipsychotics, also attenuate burying behavior. That said, the predictive validity of burying behavior as a screening test for anxiety and/or compulsive-like repetition is undermined by contradictory results - for instance, response to anxiogenic drugs (Nicolas et al., 2006) and sensitivity to a number of compounds not related to the clinical treatment of either anxiety or compulsivity (de Almeida, de Carvalho, Silva, de Sousa, \& de Freitas, 2014; Honda, Kawaura, Soeda, Shirasaki, \& Takahama, 2011; Krass, Rünkorg, Wegener, \&
Volke, 2010; Uday, Pravinkumar, Manish, \& Sudhir, 2007). Moreover, previous pharmacological studies have used mostly acute, single-dose treatments ranging from 30 to $90 \mathrm{~min}$ before recording burying behavior (Nicolas et al., 2006; Uday et al., 2007), despite antidepressants only being effective after chronic administration (Fineberg \& Craig, 2007; Huh, Goebert, Takeshita, Lu, \& Kang, 2011).

As opposed to learned or pharmacologically induced perseverative behavior, spontaneous stereotypy in the deer mouse (Peromyscus maniculatus bairdii) is a naturalistic animal model of OCD, founded on robust face, construct, and predictive validity (Güldenpfennig, Wolmarans, du Preez, Stein, \& Harvey, 2011; Korff, Stein, \& Harvey, 2008, 2009; Wolmarans, Brand, Stein, \& Harvey, 2013). Deer mouse stereotypy can generally be categorized into repetitive jumping and pattern running (Korff et al., 2008; Powell, Newman, Pendergast, \& Lewis, 1999), behaviors that correspond with the repetitive motor actions of OCD. Furthermore, deer mouse stereotypy demonstrates varying symptom intensities, as in OCD, and "time spent executing stereotypy" is employed as a marker of behavioral severity and treatment outcome (Wolmarans et al., 2013). Although deer mouse stereotypy has not yet been studied with respect to anxiety-like behavior, it demonstrates response to chronic, but not to subchronic, treatment with high doses of a selective serotonin reuptake inhibitor (SSRI) that is similarly effective in the treatment of anxiety and compulsive behavior in humans (Wolmarans et al., 2013).

Since MB may reflect both defensive/neophobic (anxietylike) and inherent (compulsive-like) burying behavior, in the present investigation we attempt to contribute to an understanding of the phenomenology of OCD by challenging an established animal model - namely, spontaneous stereotypy in the deer mouse - with MB. The aims of the present study were (1) to investigate whether the compulsive-like expression of motor behavior by high-stereotypical $(\mathrm{H})$ deer mice can be associated with unique MB behavior, relative to nonstereotypical (N) controls; (2) to assess whether deer mice habituate to burying behavior; and (3) to determine whether such behavior is attenuated by chronic (four-week), high-dose $(50 \mathrm{mg} / \mathrm{kg}$ /day) oral escitalopram (Baldwin, Brandish, \& Meron, 2008).

\section{Materials and method}

\section{Animals}

A total of 70 deer mice (males and females) were obtained from the deer mouse colony maintained and housed at the vivarium of North-West University (NWU), Potchefstroom, South Africa (Ethical Approval No. NWU-00066-10-S5). As has been reported previously (Powell et al., 1999), 
stereotypical behavior in the deer mouse is established by the age of 8 weeks, and only mice between the ages of 10 and 12 weeks were chosen as experimental subjects at the onset of behavioral assessments (Day 0). Mice were randomly chosen from different litters, without sex or weight bias, and housed in groups of six same-sex animals per cage. Earlier studies have already shown that the severity of stereotypy in deer mice is independent of sex (Hadley, Hadley, Ephraim, Yang, \& Lewis, 2006; Korff et al., 2008). One week before the onset of our behavioral assessments, each animal was allocated individually to an automatic climate-controlled laboratory cage [35 (l) $\times 20(\mathrm{w}) \times 13(\mathrm{~h}) \mathrm{cm}$; Techniplast S.P.A., Varese, Italy] and maintained at $23^{\circ} \mathrm{C}$ on a 12-h light/dark cycle (lights on at $06 \mathrm{~h} 00$ and off at $18 \mathrm{~h} 00$ ). Food and water were provided ad lib for the duration of the study. The cages were cleaned and new bedding material was added weekly.

\section{Generating behavioral data and the classification of $\mathbf{N}$ and $H$ animals}

In order to screen animals for baseline expression of stereotypy, the same protocol as published previously (Wolmarans et al., 2013) was followed. In short, all animals underwent a 12-h behavioral screening once a week for five consecutive screens. On any specific assessment day, animals were moved from their housing environment to the behavioral screening room. These areas were located on the same floor of the vivarium and were environmentally controlled with respect to temperature $\left(23^{\circ} \mathrm{C}\right)$, relative humidity $(55 \%)$, and light cycle (same as for the home cages). Subsequently, each animal was introduced to a behavioral test cage $[21(\mathrm{w}) \times 21(\mathrm{l}) \times 35(\mathrm{~h})$ cm; Accuscan Inc., Columbus, Ohio, USA] constructed from clear, translucent Plexiglas. The home cage bedding material was provided in quantities enough to cover the floor of the test cages, while also ensuring that it did not interrupt the scoring of behavioral data. Food was provided ad lib on the floor of the cage in the form of broken-up rodent chow pellets. Bottled water was provided through a tight-fit hole in the wall of each test cage. The cages were covered with lids that allowed uninterrupted airflow. The animals were introduced to these environments by $16 \mathrm{~h} 00$ and habituated for at least $2 \mathrm{~h}$ before the 12-h behavioral assessments started at the onset of the dark cycle. The test cages were cleaned after each screen.

Behavioral assessment was performed using the Fusion Animal Activity Monitoring System (Accuscan Inc., Columbus, Ohio, USA), and analyzed using the Fusion software. Each testing cage was fitted with a grid of infrared light beams that crossed the cage roughly $2 \mathrm{~cm}$ above the cage floor along the $x$-and $y$-axes (constituting a grid), and another set of beams (z-axis) that crossed the cage $10 \mathrm{~cm}$ above the cage floor, but parallel to the lower $y$-axis. Parallel beams were spaced $2.5 \mathrm{~cm}$ apart and recorded activity every time they were interrupted by movement. The number of vertical beam interruptions was used as a measure of vertical jumping activity, whereas the numbers of clockwise and counterclockwise cage revolutions were used to evaluate the expression of pattern running. During the recording session, the Fusion software generated data continuously, allowing for experimental playback and export of the behavioral reports the following day.

Following the first five behavioral screens, the animals were divided into $\mathrm{N}$ and $\mathrm{H}$ groups according to our previously published protocol (Wolmarans et al., 2013). Because the findings from previous studies had demonstrated the timeconsuming nature of stereotypy, we amended the protocol to include both the intensity (number of stereotypical counts per $30 \mathrm{~min}$ ) and frequency (number of 30-min $\mathrm{H}$ bouts per 12-h dark cycle or time spent executing stereotypy) as indicators of behavioral severity. The published criteria for defining vertical and horizontal $\mathrm{H}$ intervals are reproduced in Table 1. These data were plotted for both vertical activity (Fig. 1A) and horizontal activity (cage revolutions; Fig. 1B) and, since no distinction was made between the different forms of stereotypy, $\mathrm{H}$ animals could demonstrate stereotypical behavior in either one or both of the behavioral topographies. We subsequently included 18 animals in the $\mathrm{H}$ group (Fig. $1 \mathrm{~A}$ and $\mathrm{B}$ combined; subjects are indicated with crosses) that expressed both the highest intensity of stereotypy and the highest frequency of $\mathrm{H}$ bouts, irrespective of whether an individual did so in only one or in both of the topographies (the sum total of crosses from Fig. 1A and B-i.e., 25-exceeds 18 as more than one animal displayed $\mathrm{H}$ behavior in both topographies). The group of $\mathrm{N}$ animals was simply constituted from the 18 animals that consistently generated the lowest stereotypy counts (Fig. 1A and B combined; black dots plotted at $x=0$ ).

Because only 18 animals were included in each cohort following the first five behavioral screens, a gray margin of 34 animals were excluded from the experimental design. The rationale for the exclusion of a gray margin of animals is to improve sensitivity, as we have described elsewhere (Wolmarans et al., 2013).

\section{Marble-burying test}

In the present investigation, the MB test was applied as previously described (Broekkamp et al., 1986) with respect to the

Table 1 Criteria for defining nonstereotypical (N) and highstereotypical $(\mathrm{H})$ intervals of activity with respect to vertical activity and cage revolutions

\begin{tabular}{lll}
\hline $\begin{array}{l}\text { Stereotypy } \\
\text { Intensity }\end{array}$ & $\begin{array}{l}\text { Vertical Beam } \\
\text { Interruptions/ } \\
30 \text { min }\end{array}$ & $\begin{array}{l}\text { Cage } \\
\text { Revolutions/ } \\
30 \text { min }\end{array}$ \\
\hline $\mathrm{N}$ & $<500$ & $<150$ \\
$\mathrm{H}$ & $>2,000$ & $>200$ \\
\hline
\end{tabular}


A

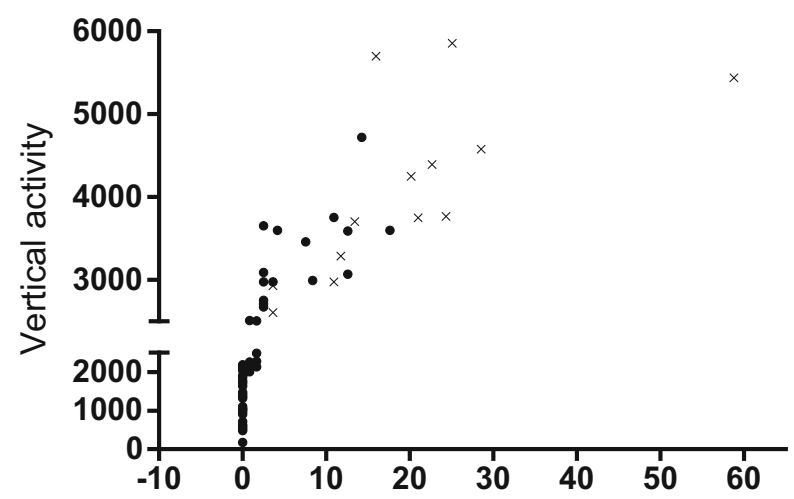

Frequency of bouts of vertical $\mathrm{H}$ behavior (\%)

B

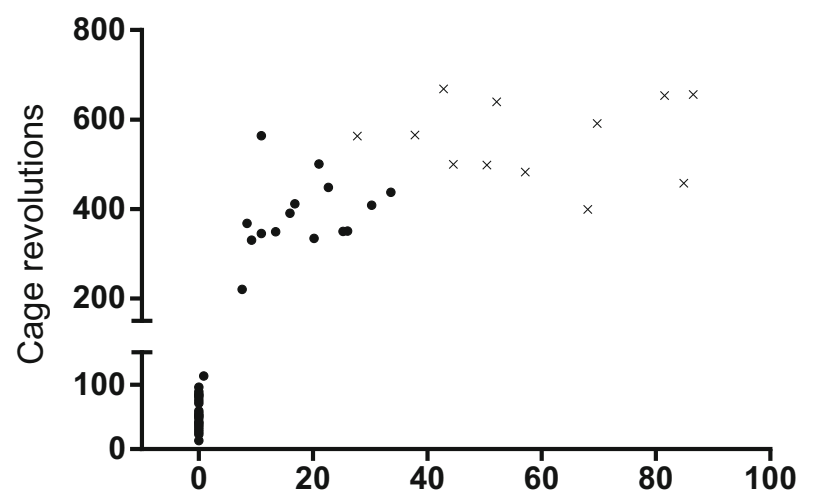

Frequency of bouts of horizontal $\mathrm{H}$ behavior (\%)

Fig. 1 Stereotypy intensity versus frequency of high-stereotypical $(\mathrm{H})$ bouts. (A) Mean of the 15 highest individual daily vertical activity scores over the first five baseline behavioral screens versus frequency of bouts of $\mathrm{H}$ activity. (B) Mean of the 15 highest individual daily cage revolution scores over the first five baseline behavioral screens versus frequency of bouts of $\mathrm{H}$ activity. Crosses indicate the $\mathrm{H}$ animals

setup for a one-zone paradigm, with slight modifications. Following the last baseline behavioral screen, the bedding material of the $18 \mathrm{~N}$ and the $18 \mathrm{H}$ animals was exchanged with sawdust. Animals were habituated in these cages in the absence of marbles for at least $24 \mathrm{~h}$ before the first MB test. All experiments were carried out under dim red light during the dark cycle. To assess MB but prevent avoidance behavior, 15 glass marbles $(\varnothing 1 \mathrm{~cm})$ were evenly spaced on sawdust (obtained from South African Vaccine Producers, Sandringham, South Africa; the average flake size was $4 \mathrm{~mm}$, in a layer $5 \mathrm{~cm}$ thick) in exact copies of the home cages. Each mouse was allocated to a marble-containing cage and allowed $30 \mathrm{~min}$ to explore. After returning the animals to their home cages, the marbles were counted. Scoring took place blindly by an observer unfamiliar with the classification status of the animals. A marble was considered buried when $2 / 3$ or more of its size was covered with sawdust. MB was measured in the same animals during three separate trials on three consecutive evenings before treatment (T1-T3), and again during three trials following four weeks of treatment (T4-T6; see the Drugs section below). Locomotor activity was assessed separately from $\mathrm{MB}$, and as stereotypy and locomotor activity were simultaneously recorded by the Fusion software, the data from the last baseline screen (pretreatment) were compared to those obtained following four weeks of treatment. Screening was performed one night before the first pre- (T1) and post(T4) treatment MB trials.

\section{Drugs}

Escitalopram oxalate was prepared for oral administration by dissolving it in the drinking water (Wolmarans et al., 2013). Physical handling of the mice was kept to a minimum to prevent any possible anxiogenic effects. For the same reason, oral gavage was not considered an appropriate dosage route. The final concentration of the drinking solution was constituted at $20 \mathrm{mg} / 100 \mathrm{ml}$, ensuring that each animal would receive $50 \mathrm{mg} / \mathrm{kg} /$ day (within close limits) of escitalopram. The dose calculation was based on a prior pilot study in which the average water intake per mouse was determined as $0.25 \mathrm{ml} /$ g/day (data are not shown), which has been confirmed by others (Aschhoff, Schroff, Wildenauer, \& Richter, 2000).

\section{Statistics}

Statistical analysis was performed using GraphPad Prism 6 and IBM SPSS Statistics 22 under the guidance of the Statistical Consultation Service of North-West University, Potchefstroom. Two-way analysis of variance followed by Bonferroni posttests was applied so as to compare the preand posttreatment expressions of MB behavior and locomotor activity both within and between $\mathrm{N}$ and $\mathrm{H}$ cohorts. Behavioral Cohort was set as a between-subjects (independent) factor, and Time and Treatment as within-subjects (dependent) factors. The same statistics were applied to compare high burying behavior (HBB) with inherent burying behavior (IBB). In this case, Burying Cohort was set as a between-subjects factor and Time and Treatment as within-subjects factors. HBB behavior was statistically separated from IBB on the basis of (1) the extent to which the average HBB scores deviated from the average IBB scores and (2) calculations of coefficients of variance in daily burying scores. Since the total average burying scores did not demonstrate a normal distribution, a Spearman's correlation between the total average number of marbles buried and the coefficients of variance was applied. As such, only animals that demonstrated burying behavior above the 75th percentile of the distribution, deviating from the mean by two times the standard deviation and that had a calculated coefficient of variance below the 25 th percentile of the distribution, were included in the HBB group. To compare 
the pre- and posttreatment locomotor activity of animals expressing HBB behavior, a two-tailed paired $t$ test was applied. Statistical significance was set at $p<.05$ for all analyses.

\section{Results}

\section{Marble-burying}

Figure $2 \mathrm{~A}$ and $\mathrm{B}$ describe the $\mathrm{MB}$ behavior in $\mathrm{N}$ and $\mathrm{H}$ deer mice that received escitalopram over three different trials. An initial evaluation of the data did not demonstrate significant differences in MB between the $\mathrm{N}$ and $\mathrm{H}$ cohorts with respect to the first trial (neophobic burying behavior), either before (Fig. 2A, T1) or after (Fig. 2A, T4) four weeks of treatment with escitalopram. Furthermore, a Pearson's correlation between the average stereotypy count and the pretreatment number of marbles buried failed to display a linear relationship [both sets of data were normally distributed, $r(34)=-.06, p=.74$; data not shown]. Moreover, chronic escitalopram failed to
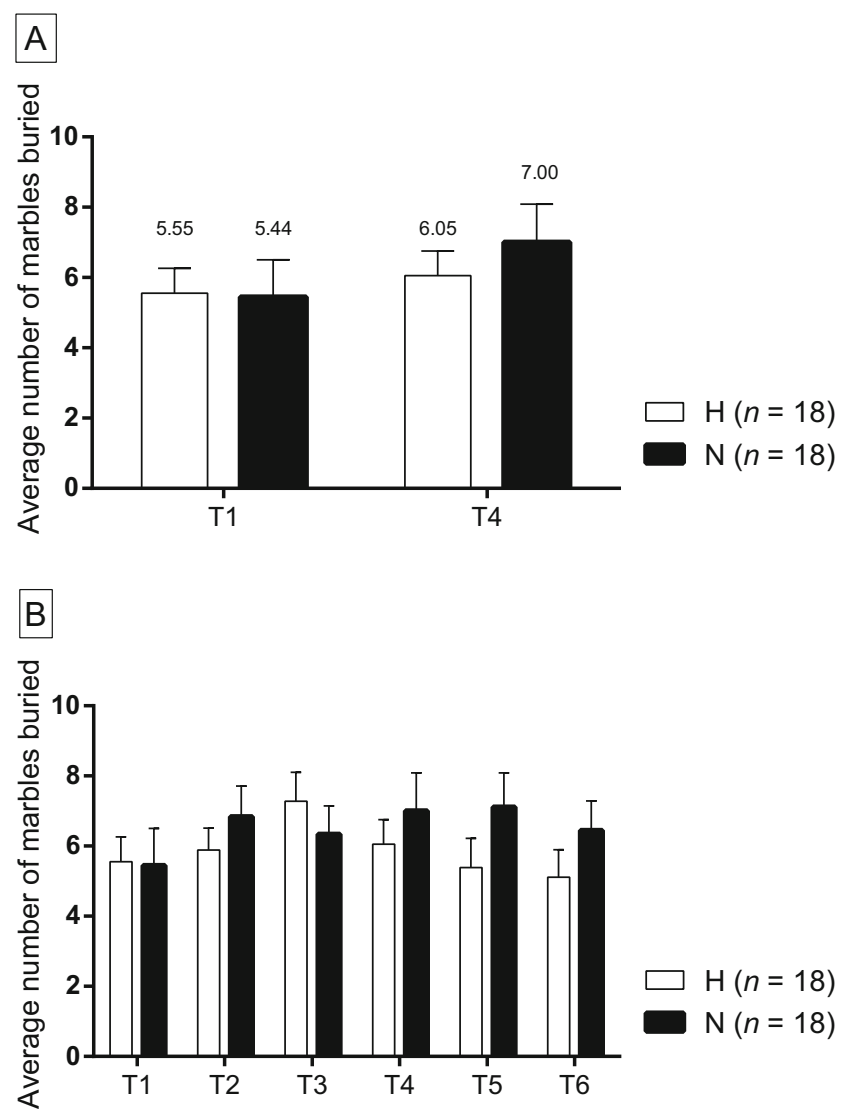

Fig. 2 Comparisons between the marble-burying behaviors of highstereotypical $(\mathrm{H})$ and nonstereotypical $(\mathrm{N})$ deer mice. (A) Comparison of the average numbers of marbles buried during the first pretreatment (T1) and first posttreatment (T4) trials. (B) Intertrial comparisons of the average numbers of marbles buried (T1-T6). Data are represented as means \pm SEMs influence the first-trial MB behavior within either of the cohorts. The average number of marbles buried throughout all pretreatment trials for $\mathrm{N}$ and $\mathrm{H}$ animals also did not differ, and treatment failed to influence this behavior either within or between behavioral cohorts (data not shown). Neither $\mathrm{N}$ nor $\mathrm{H}$ animals habituated toward burying behavior, irrespective of treatment, since no intertrial differences in MB could be observed either within or between behavioral cohorts (Fig. 2B, T1-T6).

Given the apparent lack of separation between $\mathrm{H}$ and $\mathrm{N}$ animals, the MB behavior of individual animals was analyzed independent of degree of stereotypy. A Spearman's correlation between the average numbers of marbles buried over all trials and the coefficients of variance calculated with respect to daily burying behavior revealed a strong negative association (Fig. 3A), $r(34)=-.64, p<.0001$. As such, four animals (one female, three male) were identified that consistently expressed increased MB behavior, as demonstrated by burying scores within the upper 75th percentile of the distribution, deviating by more than two standard deviations from the mean IBB score, and with little interday variance (i.e., coefficients of variance within the lower 25th percentile of the distribution). No interaction between burying behavior and treatment $[F(5,204)=0.97, p=.43]$ was demonstrated, but a significant main effect of burying cohort $[F(1,54)=17.04, p<.0001]$ was observed. This significant increase in $\mathrm{HBB}$ relative to the larger group was noted throughout all trials but one (Fig. 3B, $\left.{ }^{* *} p<.005\right)$. Furthermore, taking the average pre- $(\mathrm{T} 1-\mathrm{T} 3)$ and post- (T4-T6) treatment expressions of burying behavior together, no interaction between burying behavior and treatment $[F(1,212)=0.70, p=.4]$ was found, although again the main effect of HBB was significant $[F(1,21)=58.16, p<.0001]$, with post-hoc analysis demonstrating the significance to be even more profound (Fig. 3C, ${ }^{* * * *} p<.0005$ ).

Importantly, it must be emphasized that apart from the four animals expressing HBB behavior, all of the deer mice in the present investigation displayed IBB (Table 2). Although this behavior varied in expression between individual animals, it also varied in intensity across different trials within the same animal (Fig. 3D; data sheet included as supplementary material). In fact, apart from the consistent burying behavior of the animals expressing HBB behavior, no apparent burying pattern could be recognized in the same animal, in the same behavioral cohort, or with respect to its response to treatment (Figs. 3A, B, D).

\section{Locomotor activity}

A significant two-way interaction was evident between cohort and treatment $[F(1,34)=6.319, p=.02]$. $\mathrm{N}$ deer mice displayed a significant increase in baseline locomotor activity as compared to $\mathrm{H}$ animals (Fig. $4 \mathrm{~A},{ }^{* * * *} p<.0005$ ), whereas 


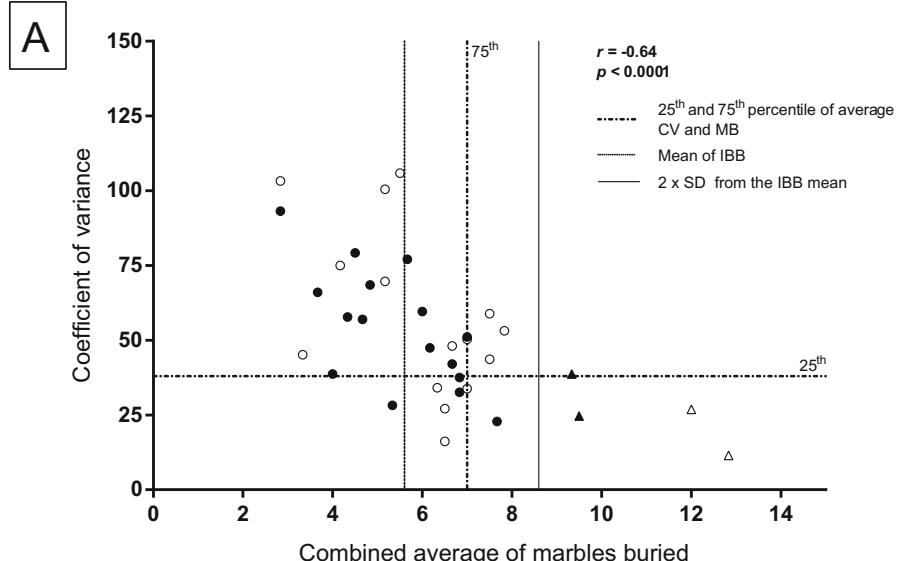

B

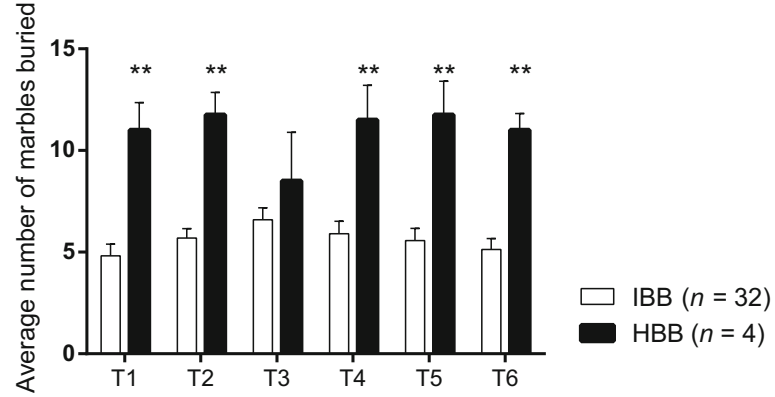

C
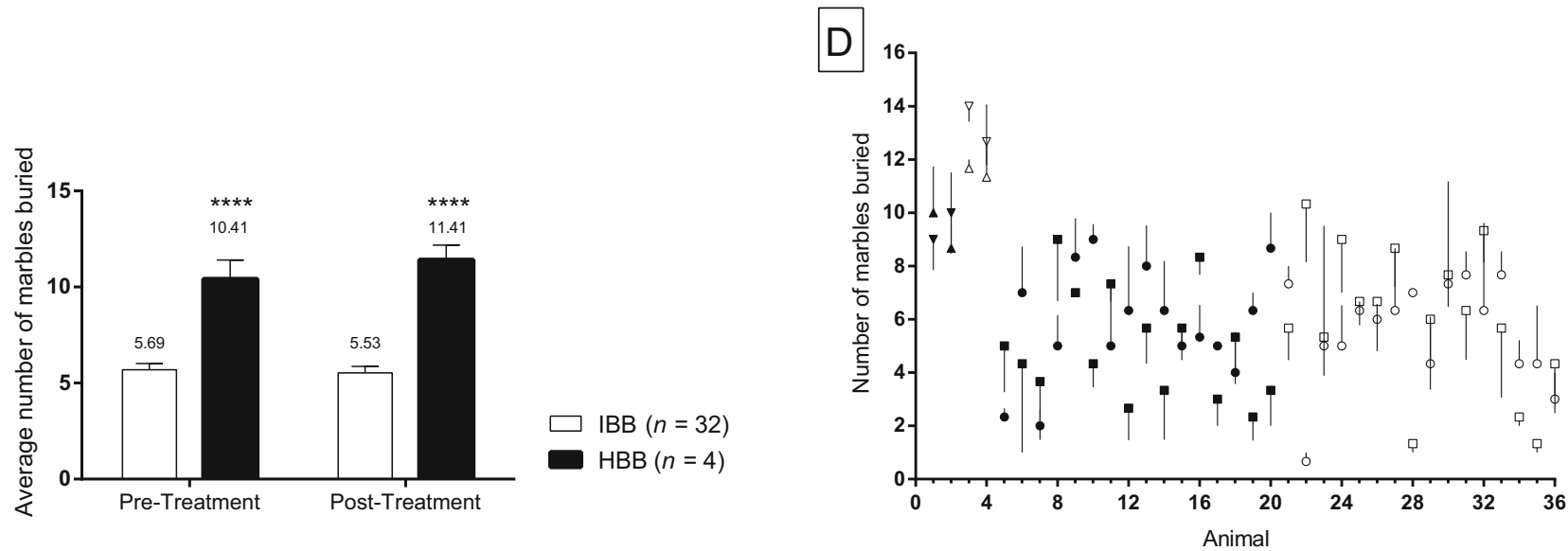

Fig. 3 Comparisons between the marble-burying (MB) behavior of animals expressing high or inherent burying behavior (HBB or IBB, respectively). (A) Coefficients of variance with respect to daily burying scores against the combined average numbers of marbles buried by each individual over all trials: closed triangles, high-stereotypical $(\mathrm{H})$ animals expressing $\mathrm{HBB}$; open triangles, nonstereotypical $(\mathrm{N})$ animals expressing HBB; closed dots, $\mathrm{H}$ animals expressing IBB; open dots, $\mathrm{N}$ animals expressing IBB; $\mathrm{CV}$, coefficient of variance; $\mathrm{SD}$, standard deviation. (B) Intertrial comparisons of the average numbers of marbles buried

chronic escitalopram treatment significantly decreased the locomotor activity of both $\mathrm{N}$ and $\mathrm{H}$ animals (Fig. $4 \mathrm{~A},{ }^{* * * *} p<$ $.0005,{ }^{*} p=.02$ ). Regarding the four animals expressing HBB, escitalopram significantly decreased locomotor activity in those animals [Fig. 4B; $t(3)=3.99,{ }^{*} p=.03$ ].

\section{Discussion}

The major findings of the present study are (1) that $\mathrm{H}$ deer mice do not present with altered MB behavior relative to $\mathrm{N}$ animals; (2) that all deer mice exhibit a level of IBB that is not subject to habituation; (3) that a characteristically different form of burying behavior (HBB) has been identified within the species, but across different behavioral cohorts; and (4) that neither IBB nor HBB behavior

(T1-T6). (C) Comparison of the average numbers of marbles buried over the three pretreatment (T1-T3) and the three posttreatment (T4 T6) trials. (D) Average pre- and posttreatment numbers of marbles buried by individual animals: closed triangles, $\mathrm{H}$ animals expressing $\mathrm{HBB}$; open triangles, $\mathrm{N}$ animals expressing HBB; upward triangles, pretreatment value; downward triangles, posttreatment value; closed squares and dots, IBB of $\mathrm{H}$ animals; open squares and dots, IBB of $\mathrm{N}$ animals; dots, pretreatment; squares, posttreatment. ${ }^{* *} p<.005,{ }^{* * * *} p<$ .0005 . Data are represented as means $\pm S E M \mathrm{~s}$

is sensitive to chronic (four-week) high-dose escitalopram treatment $(50 \mathrm{mg} / \mathrm{kg} /$ day $)$.

Although defensive and neophobic burying is a normal behavioral coping response in mice, and as such cannot be used to model a psychiatric illness (De Boer \& Koolhaas, 2003), aberrant defensive, neophobic, and inherent burying behavior, of which MB has been suggested to be an example (Broekkamp et al., 1986; Njung'e \& Handley, 1991; Thomas et al., 2009), might be useful for modeling illnesses analogous to compulsivity and anxiety. However, the diversity of the application and pharmacological sensitivity of this measure (Nicolas et al., 2006; Thomas et al., 2009) has contributed to uncertainty as to what behavioral phenotype(s) the test may in fact be measuring.

OCD responds preferentially to SSRIs, and invariably to a higher dose than the nominal antidepressant dose (El Mansari 
Table 2 Average pretreatment, posttreatment, and combined numbers of marbles buried

\begin{tabular}{|c|c|c|c|c|}
\hline Animal & $\begin{array}{l}\text { Behavioral } \\
\text { Cohort }\end{array}$ & $\begin{array}{l}\text { Pretreatment } \\
\text { Average } \\
\text { Number of } \\
\text { Marbles } \\
\text { Buried }\end{array}$ & $\begin{array}{l}\text { Posttreatment } \\
\text { Average } \\
\text { Number of } \\
\text { Marbles } \\
\text { Buried }\end{array}$ & $\begin{array}{l}\text { Combined } \\
\text { Average } \\
\text { Number of } \\
\text { Marbles } \\
\text { Buried }\end{array}$ \\
\hline 1 & $\mathrm{H}$ & 10.0 & 9.0 & 9.5 \\
\hline 2 & $\mathrm{H}$ & 8.7 & 10.0 & 9.3 \\
\hline 3 & $\mathrm{~N}$ & 11.7 & 14.0 & 12.8 \\
\hline 4 & $\mathrm{~N}$ & 11.3 & 12.7 & 12.0 \\
\hline Average & & 10.4 & 11.4 & 10.9 \\
\hline 5 & $\mathrm{H}$ & 2.3 & 5.0 & 3.7 \\
\hline 6 & $\mathrm{H}$ & 7.0 & 4.3 & 5.7 \\
\hline 7 & $\mathrm{H}$ & 2.0 & 3.7 & 2.8 \\
\hline 8 & $\mathrm{H}$ & 5.0 & 9.0 & 7.0 \\
\hline 9 & $\mathrm{H}$ & 8.3 & 7.0 & 7.7 \\
\hline 10 & $\mathrm{H}$ & 9.0 & 4.3 & 6.7 \\
\hline 11 & $\mathrm{H}$ & 5.0 & 7.3 & 6.2 \\
\hline 12 & $\mathrm{H}$ & 6.3 & 2.7 & 4.5 \\
\hline 13 & $\mathrm{H}$ & 8.0 & 5.7 & 6.8 \\
\hline 14 & $\mathrm{H}$ & 6.3 & 3.3 & 4.8 \\
\hline 15 & $\mathrm{H}$ & 5.0 & 5.7 & 5.3 \\
\hline 16 & $\mathrm{H}$ & 5.3 & 8.3 & 6.8 \\
\hline 17 & $\mathrm{H}$ & 5.0 & 3.0 & 4.0 \\
\hline 18 & $\mathrm{~N}$ & 4.0 & 5.3 & 4.7 \\
\hline 19 & $\mathrm{~N}$ & 6.3 & 2.3 & 4.3 \\
\hline 20 & $\mathrm{~N}$ & 8.7 & 3.3 & 6.0 \\
\hline 21 & $\mathrm{~N}$ & 7.3 & 5.7 & 6.5 \\
\hline 22 & $\mathrm{~N}$ & 0.7 & 10.3 & 5.5 \\
\hline 23 & $\mathrm{~N}$ & 5.0 & 5.3 & 5.2 \\
\hline 24 & $\mathrm{~N}$ & 5.0 & 9.0 & 7.0 \\
\hline 25 & $\mathrm{~N}$ & 6.3 & 6.7 & 6.5 \\
\hline 26 & $\mathrm{~N}$ & 6.0 & 6.7 & 6.3 \\
\hline 27 & $\mathrm{~N}$ & 6.3 & 8.7 & 7.5 \\
\hline 28 & $\mathrm{~N}$ & 7.0 & 1.3 & 4.2 \\
\hline 29 & $\mathrm{~N}$ & 4.3 & 6.0 & 5.2 \\
\hline 30 & $\mathrm{~N}$ & 7.3 & 7.7 & 7.5 \\
\hline 31 & $\mathrm{~N}$ & 7.7 & 6.3 & 7.0 \\
\hline 32 & $\mathrm{~N}$ & 6.3 & 9.3 & 7.8 \\
\hline 33 & $\mathrm{~N}$ & 7.7 & 5.7 & 6.7 \\
\hline 34 & $\mathrm{~N}$ & 4.3 & 2.3 & 3.3 \\
\hline 35 & $\mathrm{~N}$ & 4.3 & 1.3 & 2.8 \\
\hline 36 & $\mathrm{~N}$ & 3.0 & 4.3 & 3.7 \\
\hline Average & & 5.7 & 5.5 & 5.6 \\
\hline \multicolumn{2}{|c|}{ Standard deviation } & 2.0 & 2.4 & 1.5 \\
\hline
\end{tabular}

Animals 1-4 expressed HBB. Animals 5-36 expressed IBB. The average combined marble-burying values for Animals 1-4 fall within the upper 75th percentile of the normal distribution

\& Blier, 2006). Although stereotypy is a perseverative behavior common to a number of neuropsychiatric disorders,

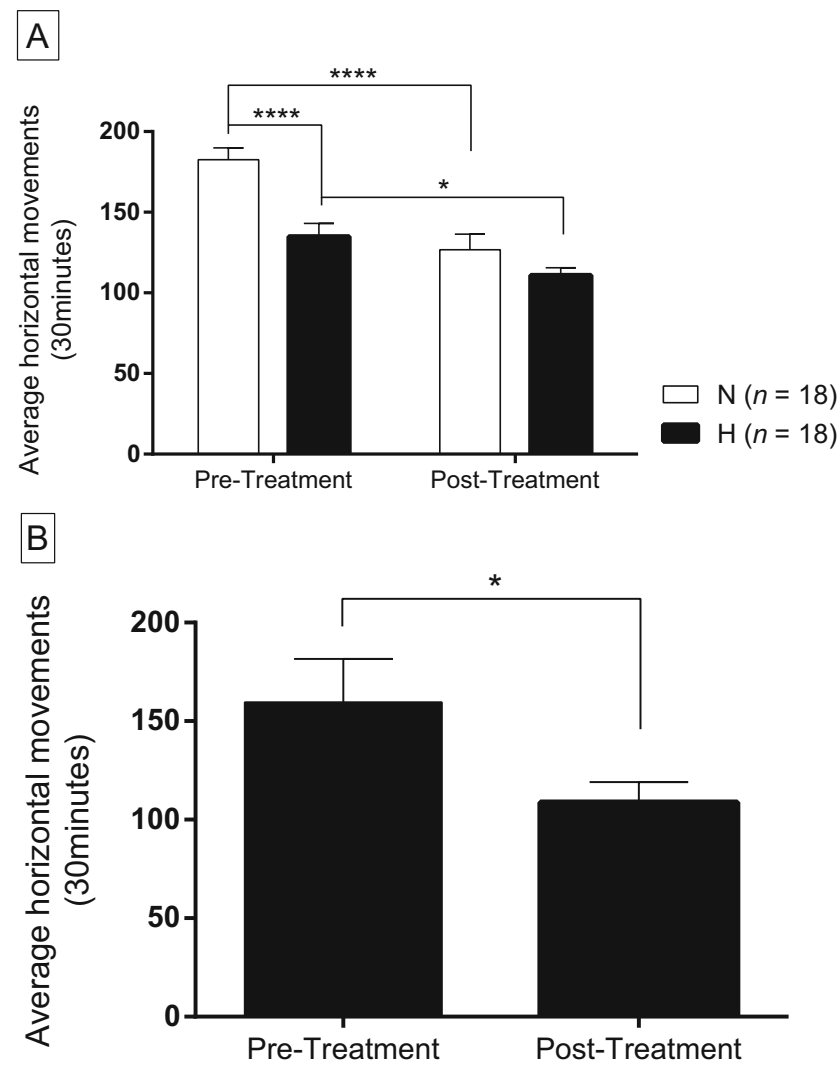

Fig. 4 Comparisons of pre- and posttreatment locomotor activity. (A) Pre- and posttreatment locomotor activity of nonstereotypical $(\mathrm{N}$, open bars) and high-stereotypical (H, closed bars) animals. (B) Pre- and posttreatment locomotor activity of animals expressing high marbleburying behavior. ${ }^{*} p<.05,{ }^{* * * *} p<.0005$. Data are represented as means \pm SEMs

including OCD (Powell et al., 1999), deer mouse stereotypy is reversed by serotonergic but not noradrenergic antidepressants (Korff et al., 2008), and chronic treatment is obligatory (Wolmarans et al., 2013). Furthermore, high stereotypy in deer mice correlates to reduced striatal serotonin transporter (SERT) density (Wolmarans et al., 2013), a recognized pathological feature of OCD (Zitterl et al., 2008), whereas SERT is also the preferential target for SSRIs (El Mansari \& Blier, 2006). In this study, we challenged $H$ animals with MB in order to screen for anxiety (neophobia) and compulsivity and to determine the response of said behavior to chronic escitalopram treatment, a known anxiety and OCD treatment modality.

The present investigation has delivered a number of fundamental observations that are relevant to $\mathrm{MB}$ behavior as a potential model for anxiety and compulsive-like behavior. Apart from MB failing to demonstrate significant differences between $\mathrm{H}$ and $\mathrm{N}$ animals (Fig. 2A and $\mathrm{B}$ ), burying behavior in deer mice is not associated with novelty-induced anxiety (neophobia, Fig. 2A). Furthermore, the nonhabituation of deer mice toward marbles (Fig. 2B) is consistent with findings published previously (Thomas et al., 2009). This observation 
and the fact that all deer mice exhibited burying behavior (Table 2) support the hypothesis that novel, but harmless and nonreactive, objects are devoid of anxiogenic properties, and that the MB test more appropriately resembles investigative, rather than anxious, behavior (Londei et al., 1998). That MB behavior varies between species (Nicolas et al., 2006), with IBB being displayed in both behavioral cohorts of deer mice $(\mathrm{N}$ and $\mathrm{H})$, suggests that $\mathrm{MB}$ behavior is a normal, not a pathological, activity within the species. This finding is congruent with the lack of response to chronic escitalopram treatment (Fig. 3B, C, and D).

Interestingly, we found that a minority of deer mice exhibit a characteristically different phenotype of burying behavior that we refer to as high burying behavior. HBB could be statistically and behaviorally distinguished from IBB and was expressed in only four of the 36 animals ( $2 \mathrm{~N}, 2 \mathrm{H}$; see Table 2 and Fig. $3 \mathrm{C}$ and D). This conclusion is based on the following data: First, a strong negative correlation was demonstrated between the average number of marbles buried over all trials and the coefficients of variance calculated from the daily burying scores (Fig. 3A). As such, HBB is statistically distinguishable from IBB in that the average pre- and posttreatment (as well as the combined) HBB values fall within the upper quartile of the burying distribution and deviate by more than twice the standard deviation from the mean IBB score (Fig. 3A, Table 2). Moreover, such behavior demonstrates very little intertrial variability (the respective coefficients of variance are contained within the lower quartile of the distribution; Fig. 3A). Second, animals expressing HBB completely buried the counted marbles underneath. As such, if face validity is considered, the phenotypical presentation of HBB behavior displayed by a small number of deer mice is characteristically different from the IBB expressed by the larger group, for which the "2/3-buried criterion" could be applied. Furthermore, as with IBB, HBB did not selectively track either the $\mathrm{H}$ or the $\mathrm{N}$ cohort, was not a result of neophobia, and did not respond to escitalopram treatment. Although we assumed HBB to be representative of compulsive behavior, given the strengths of the deer mouse model to emulate the biobehavioral and treatment response characteristics of OCD, as HBB did not selectively track $\mathrm{H}$ animals, these findings raise the question of what the behavioral and clinical significance of HBB might be. HBB might represent a unique within-species burying phenotype that resembles another behavioral manifestation related to perseverative behavior, such as hoarding. Indeed, this idea is supported by the delineation of hoarding disorder in DSM-5 (Morein-Zamir et al., 2014). Moreover, a recent study (Torres-Lista et al., 2015) demonstrated that only the number of completely buried, and not horizontally displaced or partly buried, marbles positively correlated with increased anxiety in the open-field test, supporting our view that HBB may be related to a different neuropsychological construct than is IBB.

That $\mathrm{N}$ deer mice displayed increased baseline locomotor activity relative to $\mathrm{H}$ animals (Fig. 4A) may be attributable to the manner in which locomotor activity was scored. Since H deer mice expressed significantly more vertical activity than $\mathrm{N}$ animals, they spent less time in contact with the horizontal beams (responsible for recording locomotor behavior) than did the $\mathrm{N}$ animals. Whereas previous investigations in our laboratory have shown decreased locomotor activity following chronic escitalopram treatment in the $\mathrm{N}$ cohort only (not in $\mathrm{H}$ animals; Wolmarans et al., 2013), the present data demonstrate posttreatment decreases in locomotor activity in both the $\mathrm{N}$ and $\mathrm{H}$ cohorts. Methodological differences, such as the duration of the study (12 vs. 8 weeks) could be responsible, producing an age-related downward shift in locomotor activity. However, as no changes in the expression of either IBB or HBB following treatment could be demonstrated, it is unlikely that changes in locomotor activity could have contributed in any meaningful way.

In summary, the present work has broadened our understanding of the behavioral phenotypes that may be represented by $\mathrm{MB}$ behavior. Findings from the present investigation demonstrate that all deer mice express $\mathrm{MB}$ behavior, and that such behavior is not subject to habituation and does not respond to chronic high-dose escitalopram treatment. As such, we failed to demonstrate the relevance of MB behavior as a screening test for either neophobia or compulsive-like behavior in deer mice, and suggest that such behavior is primarily investigative in nature. Furthermore, we identified a different withinspecies burying phenotype (HBB), displayed by a small minority of deer mice, that will require further investigation. Burying behavior is a natural phenomenon inherent to most rodent species, and requires experimental and methodological manipulation, such as pretest restraint (Kedia \& Chattarji, 2014) or correlations with other behavioral tests (Londei et al., 1998; Torres-Lista et al., 2015), to be a useful screening tool for either anxiety or compulsivity. Using a known OCD translational model has identified the inherent shortcomings of the MB test for obsessive-compulsive behavior, although this finding should be confirmed in other translational models (e.g., Joel \& Avisar, 2001; Szechtman et al., 2001), as well as in the promising range of genetic models currently available (Berridge, Aldridge, Houchard, \& Zhuang, 2005; Chou-Green, Holscher, Dallman, \& Akana, 2003; Shanahan et al., 2009). Given the inherent tendency of rodents to bury, we strongly argue against drawing conclusions relating to anxiety and compulsive-like behavior from a test that is dependent on MB behavior alone. Our findings further support the conclusion of De Boer and 
Koolhaas (2003) that, as far as face or predictive validity is concerned, MB behavior on its own is not a valid model for either anxiety or compulsive-like behavior.

Author note The authors thank Antoinette Fick (Good Laboratory Practice manager, Vivarium, North-West University), Faans Steyn and Marike Cockeran (North-West University Statistical Consultation Service), Sarel Brand and Linda Brand (faculty members), and Connie Sanchéz-Morillo (Lundbeck A/S) for their support and guidance. This work was funded by the South African Medical Research Council (MRC; through grants to B.H.H. and D.J.S.) and the National Research Foundation (NRF) (to B.H.H.; grant number 77323). The grant-holder acknowledges that opinions, findings and conclusions or recommendations expressed in any publication generated by NRF supported research are those of the authors, and that the NRF accepts no liability whatsoever in this regard. These funders have no other role in the study. The escitalopram used in this investigation was generously sponsored by Lundbeck A/S. Conflicts of interest: The authors declare that over the past 3 years, D.J.S. has received research grants and/or consultancy honoraria from AMBRF, Biocodex, Cipla, Lundbeck, the National Responsible Gambling Foundation, Novartis, Servier, and Sun. In the past 3 years, B.H.H. has participated in advisory boards and received honoraria from Servier and has received research funding from Servier and Lundbeck. Except for income from the primary employer and research funding to B.H.H. from the above funders, and the abovementioned exceptions, no financial support or compensation has been received from any individual or corporate entity over the past 3 years for research or professional services, and the authors have no personal financial holdings that could be perceived as constituting a potential conflict of interest.

\section{References}

Abe, M., Nakai, H., Tabata, R., Saito, K.-I., \& Egawa, M. (1998). Effect of 5-\{3-[((2S)-1,4-benzodioxan-2-ylmethyl)amino]propoxy\}-1,3benzodioxole $\mathrm{HCl}$ (MKC-242), a novel 5-HT(1A)-receptor agonist, on aggressive behavior and marble burying behavior in mice. Japanese Journal of Pharmacology, 76, 297-304. doi:10.1254/jjp. 76.297

Angoa-Pérez, M., Kane, M. J., Briggs, D. I., Francescutti, D. M., \& Kuhn, D. M. (2013). Marble burying and nestlet shredding as tests of repetitive, compulsive-like behaviors in mice. Journal of Visualized Experiments, 82, e50978. doi:10.3791/50978

Aschhoff, S., Schroff, K.-C., Wildenauer, D. B., \& Richter, E. (2000). Nicotine consumption of several mouse strains using a two bottle choice paradigm. Journal of Experimental Animal Science, 40, 171-177.

Baldwin, D. S., Brandish, E. K., \& Meron, D. (2008). The overlap of obsessive-compulsive disorder and social phobia and its treatment. CNS Spectrums, 13(9, Suppl. 14), 47-53.

Berridge, K. C., Aldridge, J. W., Houchard, K. R., \& Zhuang, X. (2005). Sequential super-stereotypy of an instinctive fixed action pattern in hyper-dopaminergic mutant mice: A model of obsessive compulsive disorder and Tourette's. BMC Biology, 3, 4. doi:10.1186/1741-7007-3-4

Broekkamp, C. L., Rijk, H. W., Joly-Gelouin, D., \& Lloyd, K. L. (1986). Major tranquillizers can be distinguished from minor tranquillizers on the basis of effects on marble burying and swim-induced grooming in mice. European Journal of Pharmacology, 126, 223-229.

Bruins Slot, L. A., Bardin, L., Auclair, A. L., Depoortere, R., \& NewmanTancredi, A. (2008). Effects of antipsychotics and reference monoaminergic ligands on marble burying behavior in mice. Behavioural Pharmacology, 19, 145-152. doi:10.1097/FBP. 0b013e3282f62cb2

Chou-Green, J. M., Holscher, T. D., Dallman, M. F., \& Akana, S. F. (2003). Compulsive behavior in the 5-HT2C receptor knockout mouse. Physiology and Behavior, 78, 641-649.

de Almeida, A. A. C., de Carvalho, R. B. F., Silva, O. A., de Sousa, D. P., \& de Freitas, R. M. (2014). Potential antioxidant and anxiolytic effects of $(+)$-limonene epoxide in mice after marble-burying test. Pharmacology Biochemistry and Behavior, 118, 69-78. doi:10. 1016/j.pbb.2014.01.006

De Boer, S. F., \& Koolhaas, J. M. (2003). Defensive burying in rodents: Ethology, neurobiology and psychopharmacology. European Journal of Pharmacology, 463, 145-161. doi:10.1016/S00142999(03)01278-0

Deacon, R. M. J. (2006). Digging and marble burying in mice: Simple methods for in vivo identification of biological impacts. Nature Protocols, 1, 122-124. doi:10.1038/nprot.2006.20

Diamant, M., Croiset, G., De Zwart, N., \& De Wied, D. (1991). Shock-prod burying test in rats: Autonomic and behavioral responses. Physiology and Behavior, 50, 23-31. doi:10.1016/ 0031-9384(91)90493-8

Egashira, N., Okuno, R., Harada, S., Matsushita, M., Mishima, K., Iwasaki, K., ... Fujiwara, M. (2008). Effects of glutamate-related drugs on marble-burying behavior in mice: Implications for obsessive-compulsive disorder. European Journal of Pharmacology, 586, 164-170. doi:10.1016/j.ejphar.2008.01.035

El Mansari, M., \& Blier, P. (2006). Mechanisms of action of current and potential pharmacotherapies of obsessive-compulsive disorder. Progress in Neuro-Psychopharmacology and Biological Psychiatry, 30, 362-373. doi:10.1016/j.pnpbp.2005.11.005

Fineberg, N. A., \& Craig, K. J. (2007). Pharmacological treatment for obsessive-compulsive disorder. Psychiatry, 6, 234-239. doi:10. 1016/j.mppsy.2007.04.001

Güldenpfennig, M., Wolmarans, D. W., du Preez, J. L., Stein, D. J., \& Harvey, B. H. (2011). Cortico-striatal oxidative status, dopamine turnover and relation with stereotypy in the deer mouse. Physiology and Behavior, 103, 404-411. doi:10.1016/j.physbeh. 2011.03.008

Gyertyan, I. (1995). Analysis of the marble burying response: Marbles serve to measure digging rather than evoke burying. Behavioural Pharmacology, 6, 24-31.

Hadley, C., Hadley, B., Ephraim, S., Yang, M., \& Lewis, M. H. (2006). Spontaneous stereotypy and environmental enrichment in deer mice (Peromyscus maniculatus): Reversibility of experience. Applied Animal Behaviour Science, 97, 312-322. doi:10.1016/j.applanim. 2005.08.006

Honda, S., Kawaura, K., Soeda, F., Shirasaki, T., \& Takahama, K. (2011). The potent inhibitory effect of tipepidine on marble-burying behavior in mice. Behavioural Brain Research, 216, 308-312. doi:10. 1016/j.bbr.2010.08.010

Huh, J., Goebert, D., Takeshita, J., Lu, B. Y., \& Kang, M. (2011). Treatment of generalized anxiety disorder: A comprehensive review of the literature for psychopharmacologic alternatives to newer antidepressants and benzodiazepines. Primary Care Companion for CNS Disorders, 13(2), e1-e9. doi:10.4088/PCC.08r00709

Joel, D., \& Avisar, A. (2001). Excessive lever pressing following posttraining signal attenuation in rats: A possible animal model of obsessive compulsive disorder? Behavioural Brain Research, 123, 7787. doi:10.1016/S0166-4328(01)00201-7

Kedia, S., \& Chattarji, S. (2014). Marble burying as a test of the delayed anxiogenic effects of acute immobilisation stress in mice. Journal of Neuroscience Methods, 233, 150-154. doi:10.1016/j.jneumeth. 2014.06.012

Korff, S., Stein, D. J., \& Harvey, B. H. (2008). Stereotypic behaviour in the deer mouse: Pharmacological validation and relevance for 
obsessive compulsive disorder. Progress in NeuroPsychopharmacology and Biological Psychiatry, 32, 348-355.

Korff, S., Stein, D. J., \& Harvey, B. H. (2009). Cortico-striatal cyclic AMP-phosphodiesterase-4 signalling and stereotypy in the deer mouse: Attenuation after chronic fluoxetine treatment. Pharmacology Biochemistry and Behavior, 92, 514-520. doi:10. 1016/j.pbb.2009.01.025

Krass, M., Rünkorg, K., Wegener, G., \& Volke, V. (2010). Nitric oxide is involved in the regulation of marble-burying behavior. Neuroscience Letters, 480, 55-58. doi:10.1016/j.neulet. 2010.06.002

Londei, T., Valentini, A. M., \& Leone, V. G. (1998). Investigative burying by laboratory mice may involve non-functional, compulsive, behaviour. Behavioural Brain Research, 94, 249-254.

Millan, M. J., Dekeyne, A., Papp, M., Drieu La Rochelle, C., Macsweeny, C., Peglion, J., \& Brocco, M. (2001). S33005, a novel ligand at both serotonin and norepinephrine transporters: II. Behavioral profile in comparison with venlafaxine, reboxetine, citalopram, and clomipramine. Journal of Pharmacology and Experimental Therapeutics, 298, 581-591.

Millan, M. J., Girardon, S., Mullot, J., Brocco, M., \& Dekeyne, A. (2002). Stereospecific blockade of marble-burying behaviour in mice by selective, non-peptidergic neurokinin1 (NK1) receptor antagonists. Neuropharmacology, 42, 677-684. doi:10.1016/ S0028-3908(02)00021-7

Morein-Zamir, S., Papmeyer, M., Pertusa, A., Chamberlain, S. R., Fineberg, N. A., Sahakian, B. J., ... Robbins, T. W. (2014). The profile of executive function in OCD hoarders and hoarding disorder. Psychiatry Research, 215, 659-667. doi:10.1016/j.psychres. 2013.12.026

Nicolas, L. B., Kolb, Y., \& Prinssen, E. P. M. (2006). A combined marble burying-locomotor activity test in mice: A practical screening test with sensitivity to different classes of anxiolytics and antidepressants. European Journal of Pharmacology, 547, 106-115. doi:10. 1016/j.ejphar.2006.07.015

Njung'e, K., \& Handley, S. L. (1991). Evaluation of marble-burying behavior as a model of anxiety. Pharmacology, Biochemistry and Behavior, 38, 63-67. doi:10.1016/0091-3057(91)90590-X

Pinel, J. P. J., \& Treit, D. (1978). Burying as a defensive response in rats. Journal of Comparative and Physiological Psychology, 92, 708-712.

Powell, S. B., Newman, H. A., Pendergast, J. F., \& Lewis, M. H. (1999). A rodent model of spontaneous stereotypy: Initial characterization of developmental, environmental, and neurobiological factors. Physiology \& Behavior, 66, 355-363. doi:10.1016/S00319384(98)00303-5
Schneider, T., \& Popik, P. (2007). Attenuation of estrous cycle-dependent marble burying in female rats by acute treatment with progesterone and antidepressants. Psychoneuroendocrinology, 32, 651-659. doi: 10.1016/j.psyneuen.2007.04.003

Shanahan, N. A., Holick Pierz, K. A., Masten, V. L., Waeber, C., Ansorge, M., Gingrich, J. A., ... Dulawa, S. C. (2009). Chronic reductions in serotonin transporter function prevent 5-HT1Binduced behavioral effects in mice. Biological Psychiatry, 65, 401-408. doi:10.1016/j.biopsych.2008.09.026

Smithers, R. H. N. (1983). XXIII. Families CRICETIDAE and MURIDAE, rats and mice. In The mammals of the SouthernAfrican subregion (1st ed., pp. 220-296). Pretoria, South Africa: University of Pretoria.

Szechtman, H., Eckert, M. J., Tse, W. S., Boersma, J. T., Bonura, C. A., McClelland, J. Z., ... Eilman, D. (2001). Compulsive checking behavior of quinpirole-sensitized rats as an animal model of obsessive-compulsive disorder (OCD): Form and control. BMC Neuroscience, 2, 4.

Thomas, A., Burant, A., Bui, N., Graham, D., Yuva-Paylor, L. A., \& Paylor, R. (2009). Marble burying reflects a repetitive and perseverative behavior more than novelty-induced anxiety. Psychopharmacology, 204, 361-373.

Torres-Lista, V., López-Pousa, S., \& Giménez-Llort, L. (2015). Marbleburying is enhanced in $3 \times \mathrm{Tg}-\mathrm{AD}$ mice, can be reversed by risperidone and it is modulable by handling. Behavioural Processes, 116 , 69-74. doi:10.1016/j.beproc.2015.05.001

Uday, G., Pravinkumar, B., Manish, W., \& Sudhir, U. (2007). LHRH antagonist attenuates the effect of fluoxetine on marble-burying behavior in mice. European Journal of Pharmacology, 563, 155-159. doi:10.1016/j.ejphar.2007.02.016

Umathe, S. N., Manna, S. S. S., \& Jain, N. S. (2012). Endocannabinoid analogues exacerbate marble-burying behavior in mice via TRPV1 receptor. Neuropharmacology, 62, 2024-2033. doi:10.1016/j. neuropharm.2011.12.030

Wolmarans, D. W., Brand, L., Stein, D. J., \& Harvey, B. H. (2013). Reappraisal of spontaneous stereotypy in the deer mouse as an animal model of obsessive-compulsive disorder (OCD): Response to escitalopram treatment and basal serotonin transporter (SERT) density. Behavioural Brain Research, 256, 545-553. doi:10.1016/j.bbr. 2013.08.049

Zitterl, W., Aigner, M., Stompe, T., Zitterl-Eglseer, K., GutierrezLobos, K., Wenzel, T., ... Thau, K. (2008). Changes in thalamus-hypothalamus serotonin transporter availability during clomipramine administration in patients with obsessive-compulsive disorder. Neuropsychopharmacology, 33, 3126-3134. doi:10.1038/npp.2008.35 